Document downloaded from:

http://hdl.handle.net/10251/51726

This paper must be cited as:

Garcia-Bernabeu, A.; Benito Benito, A.; Bravo Selles, M.; Pla Santamaría, D. (2015). Photovoltaic power plants: a multicriteria approach to investment decisions and a case study in western Spain. Annals of Operations Research. 1-12. doi:10.1007/s10479-0151836-2.

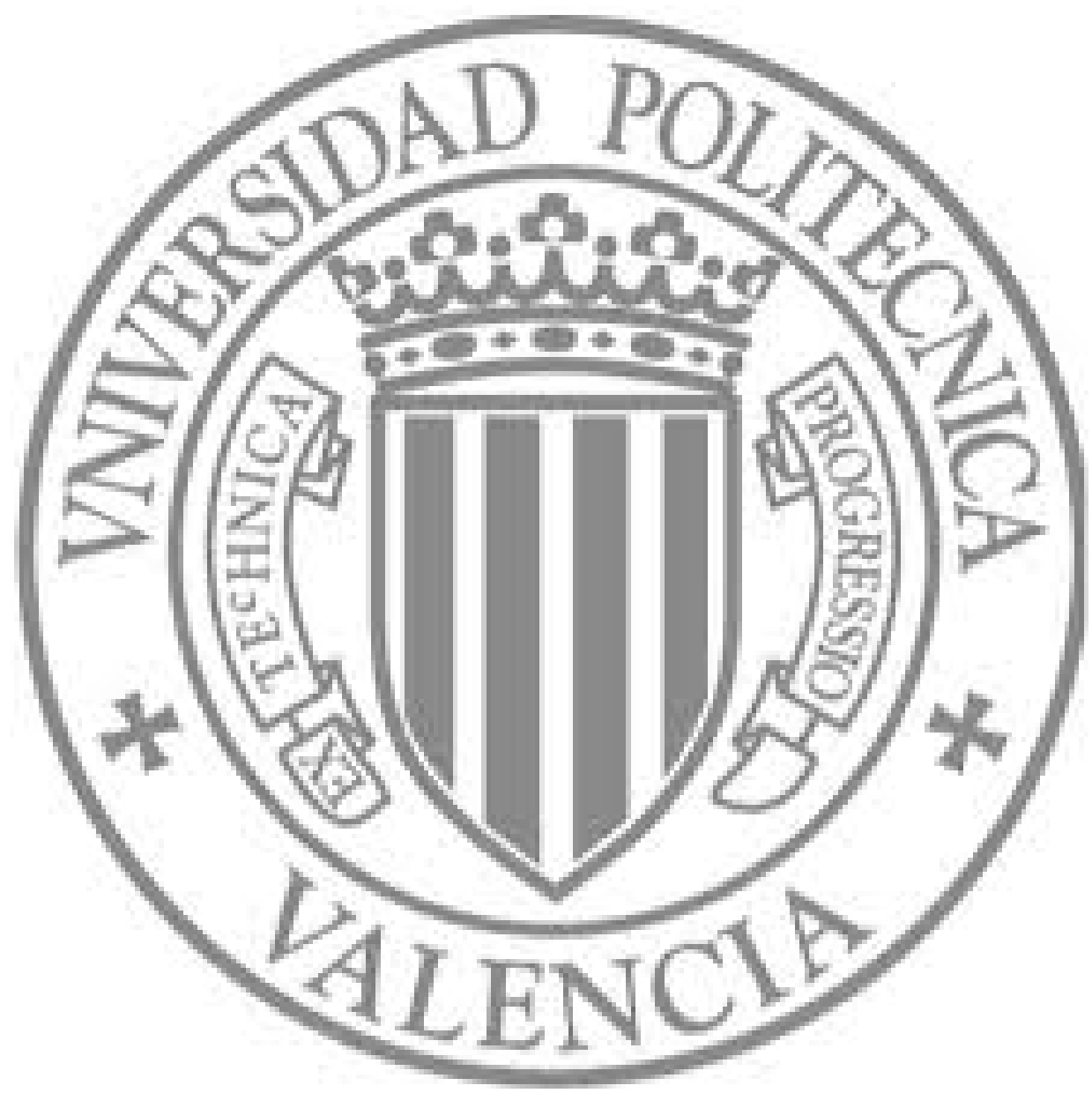

The final publication is available at

http://link.springer.com/article/10.1007\%2Fs10479-015-1836-2

Copyright Springer Verlag (Germany) 
Noname manuscript No.

(will be inserted by the editor)

\title{
Photovoltaic power plants: A multicriteria approach to investment decisions and a case study in western Spain
}

\author{
Ana Garcia-Bernabeu • Antonio Benito • \\ Mila Bravo • David Pla-Santamaria
}

Received: date / Accepted: date

\begin{abstract}
This paper proposes a Compromise Programming (CP) model to help investors decide whether to construct photovoltaic power plants with government financial support. For this purpose, we simulate an agreement between the government, who pursues political prices (guaranteed prices) as low as possible, and the project sponsor who wants returns (stochastic cash flows) as high as possible. The sponsor's decision depends on the positive or negative result of this simulation, the resulting simulated price being compared to the effective guaranteed price established by the country legislation for photovoltaic energy. To undertake the simulation, the CP model articulates variables such as ranges of guaranteed prices, technical characteristics of the plant, expected energy to be generated over the investment life, investment cost, cash flow probabilities, and others. To determine the CP metric, risk
\end{abstract}

\author{
Ana Garcia-Bernabeu \\ Universitat Politècnica de València \\ Tel.: +34-96-6528521 \\ Fax: +123-45-678910 \\ E-mail: angarber@upv.es \\ Antonio Benito \\ Universitat Politècnica de València \\ Tel.: +34-96-6528521 \\ Fax: +123-45-678910 \\ E-mail: anbebe@upv.es \\ Mila Bravo \\ Universitat Politècnica de València \\ Tel.: +34-96-6528521 \\ Fax: +123-45-678910 \\ E-mail: mibrasel@upv.es \\ David Pla-Santamaria \\ Universitat Politècnica de València \\ Tel.: +34-96-6528521 \\ Fax: +123-45-678910 \\ E-mail: dplasan@upv.es
}


aversion is assumed. As an actual application, a case study on photovoltaic power investment in Extremadura, western Spain, is developed in detail.

Keywords Compromise programming $\cdot$ renewable energy $\cdot$ guaranteed prices $\cdot$ stochastic cash flows $\cdot$ multicriteria decision making analysis

\section{Introduction}

Renewable energy is defined as a result of natural processes which are replenished along the time [2]. Although this definition is quite precise, it says nothing about viability, which depends on the type of investment and the plant location. Well-known types of renewable energy are solar power, wind, geothermal, biomass, hydropower, ocean, hydrogen and fuel cells, among others. New types are arising, e.g., renewable energy from piezoelectric ceramics [21]. Solar power includes a variety of technologies such as photovoltaic systems, solar hot water, solar electricity, passive solar heating and daylighting ${ }^{1}$, solar process space heating and cooling ${ }^{2}$. Their technical enhancement is remarkable (see, e.g., [1]); however, some of them require government financial support to be viable. A feasibility analysis is provided by [34], [12]. Photovoltaic levelized cost of electricity as a significant question is reviewed in [13]. In the United States, only a few states (Colorado, Texas, Ohio) have enacted significant policies of renewable energy. In other countries, this support is motivated by cultural factors and attitudes, political systems, and especially, the moral duty of making sustainable the legacy of natural resources ([17]). In some European countries, this support is implemented via prices while other countries prefer tax incentives [2]. Concerning Asia, the China case is examined in [38]. On problems of financing expensive projects of renewable energy by project finance, see [31]. Research on this issue in Germany reveals that investors prefer projects with premium brand technology to low-cost technology [24]. Requirements of transparency and credibility are addressed in the environmental, social and government (ESG) framework. Research on this issue encompasses matters such as external control [15], experts opinions [22], control companies [27], communication with investors [29], selection processes [27], [32] and others.

Compromise programming (CP) [37], [36] is appropriate to make decisions in many fields such as finance, engineering, management and so on. Given that no method can be presented as superior to others, in this problem CP is useful because can find the efficient alternative closest to a referential infeasible alternative (ideal point). An advantage over other capital budgeting techniques is that these techniques assume certainty (See [16], Chapter 2) while the proposed method assumes uncertainty. $\mathrm{CP}$ is frequently used to solve multicriteria decision making problems when the variables are uncertain, such as in portfolio selection problems (see, for example, [11], [8], [9], [10], [7], [30]). As an example

\footnotetext{
1 http://www.renewableenergyworld.com/rea/tech/solar-energy/solarpassive

2 http://www.renewableenergyworld.com/rea/tech/solar-energy/solarprocessheat
} 
of non-related portfolio selection problems combining $\mathrm{CP}$ with stochastic variables see [33]. Other papers related to multicriteria decision making (MCDM) methods applied to renewable energy problems are, for example, [25], [18], [35], [20] .

The aim of this work is to develop a CP model to find a compromise solution taking into account both the sponsors' and governments interest in order to construct a photovoltaic power plant with government financial support. From the sponsor's point of view, returns should be as high as possible, namely, the energy price should be as high as possible. In contrast, the government wants to agree an energy price as low as possible, which is acceptable for consumers and industrial firms in the country as well as for inflation control. Then the variable to be considered in the model is the simulated energy price, which must be less than (or equal to) the government guaranteed price.

Let us better explain the objectives of the current paper.

1. First objective. To propose a compromise programming model to obtain a simulated energy price to help the decision maker (sponsor) to make a satisfying decision about the "to invest or not to invest" dilemma.

2. Second objective. To develop a case study concerning a photovoltaic power project in the province of Extremadura, western Spain. This project was designed in year 2010 for a photovoltaic power plant, whose technical characteristics are described in Section 3. Investment life was estimated in 25 years.

Therefore, unlike Goal Programming (GP), the CP ideal is not a target established by the decision maker from his own views and judgments. GP stems from the Simonian paradigm describing decision makers as seekers of satisfying solutions rather than optimal solutions. The CP solution is obtained by minimizing the distance between a frontier basket and the ideal. As compared to goal programming, compromise programming is rooted firmly in the Pareto system of optimizing rather than the Simonian system of satisficing, although goal programming is a powerful method of decision [3]. Combining CP with fuzzy set analysis (as suggested in a working paper by [26]) is also appealing in our context to describe the government's and the sponsor's criteria in an imprecise way.

The paper is organized as follows. In Section 2, the proposed method is analytically formulated by starting with technological and economic concepts related to solar power plants. In Section 3, the case study is developed through numerical tables. The paper closes with concluding remarks.

\section{Methodology}

An investor potentially interested in the renewable energy sector has the opportunity of constructing a photovoltaic power plant on a predetermined site from an advanced project of engineering. This decision maker (here called the 
sponsor) would undertake the investment with government financial support, which is granted via prices assigned to renewable energy projects. The political price for photovoltaic investments is called the guaranteed price. To make a satisfying decision about the "to invest or not to invest" dilemma, the sponsor simulates an agreement between the government, who wants political prices as low as possible, and the investor, who wants stochastic returns as high as possible.

The method relies on the simulation of an agreement between the government agency ( briefly called "the G agency") and the sponsor. Accordingly, we simulate this agreement in the following terms.

(i) The G agency accepts to pay a political price for the energy generated by the photovoltaic power plant.

(ii) The sponsor accepts to meet technical and environmental conditions under government control.

To reconcile opposing interests and to achieve an equitable agreement, an arbiter is designated to manage the process [5]. In the current paper, the role of the arbiter is played by the analyst, who uses CP to look for a compromise solution to the agreement, thus obtaining simulated prices for the energy. This simulation does not involve assuming a particular modality of agreement such as project finance [28], [19].

We use the following notation and definitions:

$p=$ energy price (euros per $\mathrm{kWh}$ ), which is obtained by the CP model as previously noted.

$p_{0}=$ guaranteed energy price.

$p_{\text {gmax }}=$ highest energy price acceptable by the government.

$p_{\text {smin }}=$ lowest price accepted by the sponsor. This price derives from the probability of obtaining positive cash flows (see subsection 2.3 below).

$\tilde{e}=$ Stochastic annual energy ( $\mathrm{kWh}$ a year) to be produced by the solar power plant. This is a sthocastic variable, as depending on stochastic variables such as solar radiation, temperature, network losses and so on. This is an observable datum for the analyst, although an uncertain datum [23], [14]. For a single period of time, such as a month, the average values for irradiation in a given territory can present high differences depending on the reference source used for estimation. This is a consequence of the uncertain character of the solar radiation. It cannot be stated that one of the typical records for a given period is more representative than others. Future records may follow that records with the same probability.

$\tilde{R}=p \tilde{e}=$ Stochastic annual revenue to be received by the sponsor. This is a stochastic variable as energy production is uncertain.

In our context, cash flows are stochastic variables as the revenues are uncertain. These variables are critical in the simulated agreement together with 
the energy price. Guarantees are not given by the sponsor but they are only given by the cash flows themselves.

We consider the following costs. First, capital cost which should be annualized. Second, operating, maintenance and environmental costs. Third, yearly financial costs. The interest rate to be charged depends on risk, which is not previously known. Indeed, the financial cost will be established later by the bank, once the bank knows the terms of the simulated agreement, risk and so on. Then, as an example, we here propose a rate between 5 percent and 10 percent tentatively.

Notation for these costs is as follows.

$C_{1}=$ annual amortization cost (euros a year).

$C_{2}=$ operating, maintenance and environmental cost (euros a year).

$C_{3}=$ financial cost (euros a year).

$C=C_{1}+C_{2}+C_{3}=$ annual total cost.

Cash flows to be received by the sponsor, expressed in euros/year, are as follows:

$$
\tilde{F}=\tilde{R}-C
$$

Let $p$ be the resulting simulated price. If $p$ is less than (or equal to) guaranteed price $p_{0}$, then the simulation advises to invest. Then, the sponsor's decision is made as follows:

$$
\text { To agree if } \quad p<=p_{0} ; \quad \text { Not to agree if } \quad p>p_{0}
$$

\subsection{Probability of receiving positive cash flows}

We start with the following statements.

Assumption 1. Stochastic annual energy $\tilde{e}$ is normally distributed with mean value $\bar{e}$ and standard deviation $\sigma_{e}$. Mean value and variance are estimated by the analyst from previous experiences.

Property 1. From Assumption 1, stochastic annual cash flow $\tilde{F}$ is normally distributed as follows:

$$
N=N\left(\bar{F}, \sigma_{F}\right)=N\left(p \bar{e}-C, p \sigma_{e}\right)
$$

From the tabulated standardized values of normal distribution (2), probability $B(p)$ of receiving positive cash flows for a given price $p$ on the project is obtained, namely:

$$
B(p)=\operatorname{prob}(F \geq 0)
$$

In this sense, $B\left(p_{\text {smin }}\right)$ will be the lowest probability of positive cash flows accepted by the sponsor, and $B\left(p_{\text {gmax }}\right)$ will be the probability of positive cash flows given the guaranteed energy price established by the $\mathrm{G}$ agency (see subsection 2.2 below). 
The government cannot accept energy prices too high because of inflation problems and consumers claims. Therefore, the arbiter/analyst should ask the $\mathrm{G}$ agency about the highest energy price acceptable by the government. Thus, the following dialogue between the arbiter/analyst and the $\mathrm{G}$ agency is proposed.

Arbiter/analyst:

— "Which would be the highest energy price $\left(p_{\text {gmax }}\right)$ acceptable by the government?" -

\section{G agency:}

— "Around 0.2 euros per kWh" -

Obviously, $p_{\operatorname{gmax}}=0.2$ is a mere example of an answer. As this is a simulated dialogue, we estimate the answer from observed historical trends in guaranteed prices.

On the opposite side of the problem, we face the opinion of the project sponsor, who fears energy prices might be too low. From his point of view, the lower the energy price, the higher the probability of losses in the project. This leads us to the following dialogue between the arbiter/analyst and the sponsor.

\section{Arbiter/analyst:}

- "Consider the probability of benefit from the project in the form of earning positive cash flows. In your opinion, which would be the lowest level acceptable for this probability?"

\section{Sponsor:}

\section{- "Around 80\%"}

Therefore, in this illustrative example, we would have, $B\left(p_{\text {smin }}\right)=80 \%$.

From equation (2) and price $p_{\text {gmax }}$ given by the dialogue between the arbiter/analyst and the $\mathrm{G}$ agency, we obtain $B\left(p_{\text {gmax }}\right)$.

From equation (3) and probability $B\left(p_{\text {smin }}\right)$, given by the dialogue between the arbiter/analyst and the sponsor, we obtain $p_{\text {smin }}$, namely, the minimum price acceptable by the sponsor.

\subsection{CP model for photovoltaic power plants}

Faced with the simulated agreement, each party, the $\mathrm{G}$ agency and the sponsor, is concerned with a different criterion, which leads to the decision variables $x_{1}$ and $x_{2}$ as follows:

(i) G agency criteria. As noted, the major concern of the $\mathrm{G}$ agency is the energy price. The government wants to agree an energy price as low as possible, which is acceptable for consumers and industrial firms in the country as well as for inflation control. As the energy price behaves as "the more the worse", this price is normalized and measured on "the more the better" scale by this change of variable: 


$$
x_{1}=\left(p_{\text {gmax }}-p\right) /\left(p_{\text {gmax }}-p_{\text {smin }}\right) ; \quad 0 \leq x_{1} \leq 1
$$

which is the decision variable for the G agency.

(ii) Sponsor criteria. Concerning the sponsor, the criterion is different since this company is interested in receiving positive cash flows, which means having probability $B(\mathrm{p})$ greater than zero, this probability being as higher as possible. Therefore, "the more the better" normalized decision variable for the sponsor is as follows:

$$
x_{2}=B(p)-B\left(p_{\text {smin }}\right)
$$

In this CP model, the space of criteria corresponds to the space of decision variables. The $\mathrm{CP}$ ideal point is an infeasible point representing the best for each party. As to the $\mathrm{G}$ agency, the ideal is a normalized energy price $x_{1}^{*}=1$, while the ideal for the sponsor is $x_{2}^{*}=B\left(p_{\text {gmax }}\right)-B\left(p_{\text {smin }}\right)$.

In Figure 1, the CP setting is graphed.

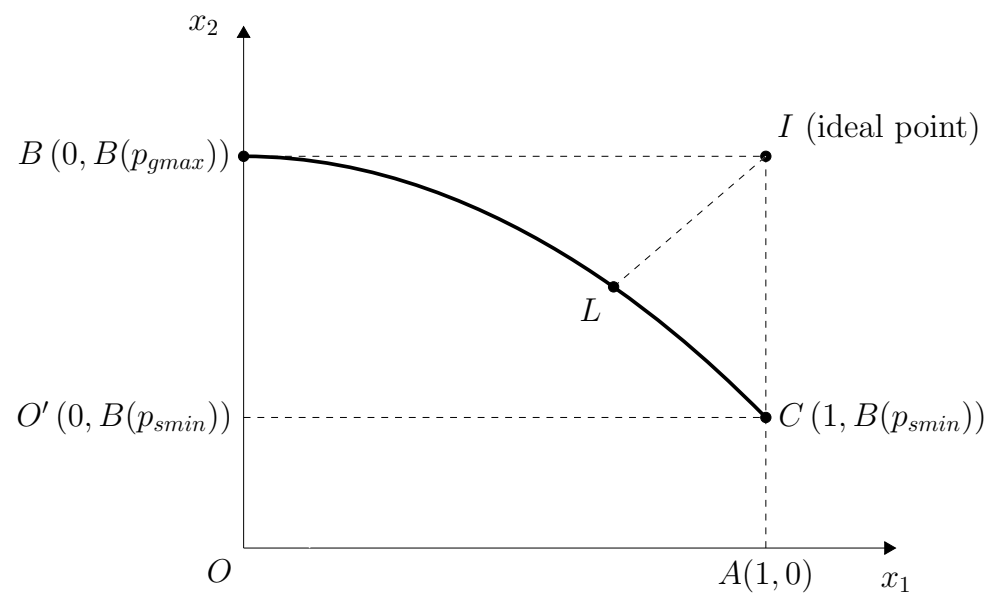

Fig. 1 Compromise Programming setting

This figure is a standard CP setting for two criteria. On the horizontal axis, we take the normalized energy price, which behaves "the more the better". On the vertical axis, we take the probability of receiving cash flows greater than 1. Point $I\left(x_{1}^{*}, x_{2}^{*}\right)$ is the ideal or anchor value where the ideal value for the $\mathrm{G}$ agency is $x_{1}^{*}=1$ and the ideal value for the sponsor is $x_{2}^{*}=B\left(p_{\text {gmax }}\right)-$ $B\left(p_{\text {smin }}\right)$

Curve BLC is a CP univocal frontier. According to Zeleny's axiom of choice [37], we have the following objective function:

$$
\min \left[w_{1}^{h}\left(x_{1}^{*}-x_{1}\right)^{h}+w_{2}^{h}\left(x_{2}^{*}-x_{2}\right)^{h}\right]^{1 / h}
$$


where,

$w_{1}$ and $w_{2}$ are preference weights for the first and second criteria, respectively. As neutral weights, we take $w_{1}=w_{2}=0.5$.

$h$ is the CP metric $1 \leq h \leq \infty$.

Minimization (4) is subject to the following constraint:

$$
p_{\text {smin }} \leq p \leq p_{\text {gmax }}
$$

together with the non-negativity conditions.

Constraint (5) implies that price must range between $p_{\text {gmax }}$ and $p_{\text {smin }}$, namely, between the highest price acceptable by the government and the lowest price acceptable by the sponsors.

In $\mathrm{CP}$, distances are not generally measured with the Euclidean metric but with a metric other than 2 . In most applications, the usual metrics are either 1 (Linear metric) or $\infty$ (infinity metric), also called the infinity norm. Linear metric is appealing to decision makers (DMs) who seek large outcomes involving imbalanced solutions in exchange for balanced (non-corner) solutions. In contrast, higher metrics such as the quadratic one or even higher are more appealing to DMs who turn to the precautionary principle of avoiding corner solutions. An extreme metric for the balancing purpose is the infinity norm. We assume risk aversion, which involves using the infinity norm or any very high metric (see [4], [6]). After this, we will carry out a sensitivity analysis to compare results.

\section{Case study}

This case deals with project Ermita, a solar power plant in Extremadura, western Spain. Although "Ermita" is a fictitious name, this is a real world project, whose features and technical data are described as follows.

- Project date: 2010

- Distances from the plant to Madrid and Lisbon: $250 \mathrm{~km}$ and $400 \mathrm{~km}$, respectively.

- Nominal power output: $5000 \mathrm{~kW}$.

- Crystalline cell modules.

- Land: 28 hectares (Type II in the Spanish legislation).

- Useful life of the project: 25 years.

\subsection{Information on energy}

In Table 1, precise estimates of energy to be generated by the solar power plant over 25 years from the installation date are displayed. Energy to be produced is a stochastic variable depending on uncertain variables such as sunny days, temperature, and others. This table gives us energy expected values. To estimate variability, we first estimate a coefficient of variation from previous technical data. From this coefficient, we estimate the standard deviation. 
Table 1 Project Ermita: Yearly energy production

\begin{tabular}{ccccc}
\hline Year t & $(1)$ & $(2)$ & $(3)$ & $(4)$ \\
\hline 1 & 0.994982 & 5969.89 & 9984.37 & 9508.92 \\
2 & 0.987012 & 5922.07 & 9904.39 & 8983.58 \\
3 & 0.981090 & 5886.54 & 9844.97 & 8504.45 \\
4 & 0.975204 & 5851.22 & 9785.90 & 8050.88 \\
5 & 0.969352 & 5816.11 & 9727.18 & 7621.50 \\
$\ldots$ & $\ldots$ & $\ldots$ & $\ldots$ & $\ldots$ \\
15 & 0.912737 & 5476.42 & 9159.06 & 4405.66 \\
16 & 0.907260 & 5443.56 & 9104.11 & 4170.70 \\
$\ldots$ & $\ldots$ & $\ldots$ & $\ldots$ & $\ldots$ \\
23 & 0.869834 & 5219.01 & 8728.55 & 2841.76 \\
24 & 0.864615 & 5187.69 & 8676.18 & 2690.20 \\
25 & 0.859428 & 5156.57 & 8624.12 & 2546.73 \\
\hline
\end{tabular}

Column description. (1) $g_{t}=$ reduction multiplier. (2) $W_{\text {peak, } t}=$ peak power in year $t$. (3) Expected energy $e_{t}$ in year $t$ (units: $000 \mathrm{kWh}$ ). (4) Expected energy (3) discounted at rate $5 \%$ (units: $000 \mathrm{kWh}$ ).

Variables in Table 1 are computed from the following data. (a) Nominal power of the installation $\left(W_{n o m}\right)$. This variable is defined by the manufacturer and it is supervised by the Public Administration. In our context, $W_{n o m}$ is fixed at level $5000 \mathrm{~kW}$. (b) Gross hours $\left(H_{B}\right)$. These depend on the expected solar radiation determined by the plant location. Herein, $H_{B}$ is estimated at 2136 hours a year. Reduction coefficients are defined as follows. (i) Performance ratio for high-voltage $(A T)$. This depends on variables such as: atmospheric temperature, efficiency of the plant, energy losses, etc. In our context, AT reaches 0.7989. (ii) Performance for medium-low voltage (MT-BT). This coefficient is estimated at 0.985 . (iii) Coefficient for breakdowns and mechanical faults. Its value is 0.995 .

The computation process is as follows:

$W_{\text {peak }}=$ peak power $=1.2 W_{\text {nom }}=1.2 \times 5000 \mathrm{~kW}=6000 \mathrm{~kW}$

$W_{\text {peak }, t}=$ peak power in each year $=g_{t} W_{\text {peak }}$, where $g_{t}$ is a reduction coefficient given in Table 1 .

$H_{N}=$ Net hours $=0.995 \times 0.985 \times 0.7989 H_{B}=0.782981918 H_{B}=0.782981918 \times$

$2136=1672$ hours.

$e_{t}=W_{\text {peak,t }} H_{N}$ in $\mathrm{kWh}$.

$\bar{e}=$ mean value of discounted expected energy, which appears at the bottom of Table 1 (last column).

$\sigma_{e}=0.034 \times 5309.86=180.87$. This standard deviation is computed by assuming a coefficient of variation equal to $3.4 \%$. 
3.2 Information on costs

In Table 2, expectations on costs over 25 years since the installation date are recorded. Prices and costs are specified in deflacted euros referred to year 2010.

Table 2 Project Ermita: Costs in 000 euros

\begin{tabular}{cccccccccc}
\hline Year t & $(1)$ & $(2)$ & $(3)$ & $(4)$ & $(5)$ & $(6)$ & $(7)$ & $(8)$ & $(9)$ \\
\hline 1 & 933.93 & 300.78 & 0.00 & 14.98 & 5.76 & 321.52 & 1587.68 & 2843.13 & 2707.74 \\
2 & 933.93 & 300.78 & 0.00 & 14.86 & 5.70 & 321.34 & 1524.17 & 2779.45 & 2521.04 \\
3 & 933.93 & 300.78 & 14.25 & 14.77 & 5.67 & 335.47 & 1460.67 & 2730.07 & 2358.33 \\
4 & 933.93 & 300.78 & 14.25 & 14.68 & 5.63 & 335.35 & 1397.16 & 2666.44 & 2193.68 \\
5 & 933.93 & 300.78 & 14.25 & 14.59 & 5.60 & 335.23 & 1333.65 & 2602.81 & 2039.37 \\
& & & & & & & & & \\
15 & 933.93 & 300.78 & 73.70 & 13.74 & 5.27 & 393.50 & 698.58 & 2026.01 & 974.54 \\
16 & 933.93 & 300.78 & 73.70 & 13.66 & 5.24 & 393.39 & 635.07 & 1962.39 & 898.99 \\
& & & & & & & & & \\
23 & 933.93 & 300.78 & 73.70 & 13.09 & 5.03 & 392.61 & 190.52 & 1517.06 & 493.91 \\
25 & 933.93 & 300.78 & 73.70 & 13.01 & 5.00 & 392.50 & 127.01 & 1453.44 & 450.67 \\
\hline & 933.93 & 300.78 & 73.70 & 12.94 & 4.97 & 392.39 & 63.51 & 1389.83 & 410.42 \\
\hline
\end{tabular}

Column description. (1) Asset physical depreciation and obsolescence cost $C_{1 t}$ in year $t$. (2) Maintenance, insurance, rent, and others. (3) Spare parts. (4) Marketing expenses. (5) Taxes. (6) Cost $C_{2 t}$ in year $t$, namely, the sum of columns from (2) to (5), both inclusive. (7) Financial cost $C_{3 t}$ in year $t$. (8) Aggregate cost $C_{t}$ in year $t$, namely, the sum of columns (1), (6) and (7) for costs $C_{1 t}, C_{2 t}$ and $C_{3 t}$, respectively. (9) Present value $C_{t}^{0}$ of $C_{t}$ in year t.

Physical depreciation and obsolescence cost, which remain constant along the time, is computed by the following equation:

$$
\text { annual depreciation cost }=\frac{\text { investment cost }- \text { residual value }}{\text { uselful life of the project }}
$$

Financial costs are computed as follows. To construct the plant, a loan of $80 \%$ of the investment cost is taken, namely,

$0.80 \times 23348.25=18678.60$ (thousands of euros)

Interest rate is $8.5 \%$. As shown in the table, financial costs decrease over time as the annuity of principal to be repaid decreases.

Aggregate cost $C_{t}$, which is recorded in column (8), is discounted at rate $5 \%$, thus obtaining $C_{t}^{0}$ displayed in column (9). At the bottom of this column, mean value $\bar{C}$ of these costs is shown. 
3.3 Stochastic cash flows and their probabilities

In Table 3, standardized cash flows, which are assumed to be governed by a normal distribution, are displayed. In the last columns, probabilities related to these cash flows are recorded.

Table 3 Project Ermita: Standardized normal $\theta$ stochastic cash flow and their probabilities

\begin{tabular}{rrrrrrrr}
\hline$(1)$ & $(2)$ & $(3)$ & $(4)$ & $(5)$ & $(6)$ & $(7)$ & $(8)$ \\
\hline 0.2322 & 1232.96 & 1291.39 & -58.43 & 41.9992 & 1.39122 & 0.082079 & 0.917921 \\
0.2349 & 1247.46 & 1291.39 & -43.92 & 42.4933 & 1.03369 & 0.150640 & 0.849360 \\
0.2377 & 1261.97 & 1291.39 & -29.42 & 42.9874 & 0.68438 & 0.246869 & 0.753131 \\
0.2404 & 1276.47 & 1291.39 & -14.91 & 43.4815 & 0.34300 & 0.365799 & 0.634201 \\
0.2431 & 1290.98 & 1291.39 & -0.41 & 43.9756 & 0.00929 & 0.496292 & 0.503708 \\
0.2459 & 1305.48 & 1291.39 & 14.10 & 44.4697 & -0.31699 & 0.624376 & 0.375624 \\
0.2486 & 1319.99 & 1291.39 & 28.60 & 44.9638 & -0.63611 & 0.737648 & 0.262352 \\
$\mathbf{0 . 2 4 8 9}$ & $\mathbf{1 3 2 1 . 7 6}$ & $\mathbf{1 2 9 1 . 3 9}$ & $\mathbf{3 0 . 3 7}$ & $\mathbf{4 5 . 0 2 4 0}$ & $-\mathbf{0 . 6 7 4 4 9}$ & $\mathbf{0 . 7 5 0 0 0 0}$ & $\mathbf{0 . 2 5 0 0 0 0}$ \\
0.2513 & 1334.50 & 1291.39 & 43.11 & 45.4579 & -0.94829 & 0.828510 & 0.171490 \\
0.2541 & 1349.00 & 1291.39 & 57.61 & 45.9520 & -1.25376 & 0.895035 & 0.104965 \\
0.2568 & 1363.51 & 1291.39 & 72.12 & 46.4461 & -1.55273 & 0.939756 & 0.060244 \\
0.2595 & 1378.01 & 1291.39 & 86.62 & 46.9402 & -1.84540 & 0.967510 & 0.032490 \\
$\mathbf{0 . 2 6 0 0}$ & $\mathbf{1 3 8 0 . 5 6}$ & $\mathbf{1 2 9 1 . 3 9}$ & $\mathbf{8 9 . 1 8}$ & $\mathbf{4 7 . 0 2 7 2}$ & $-\mathbf{1 . 8 9 6 2 9}$ & $\mathbf{0 . 9 7 1 0 3 9}$ & $\mathbf{0 . 0 2 8 9 6 1}$ \\
0.2623 & 1392.52 & 1291.39 & 101.13 & 47.4344 & -2.13198 & 0.983496 & 0.016504 \\
0.2650 & 1407.02 & 1291.39 & 115.63 & 47.9285 & -2.41264 & 0.992081 & 0.007919 \\
0.2677 & 1421.53 & 1291.39 & 130.14 & 48.4226 & -2.68758 & 0.996401 & 0.003599 \\
0.2705 & 1436.03 & 1291.39 & 144.65 & 48.9167 & -2.95697 & 0.998447 & 0.001553 \\
\hline
\end{tabular}

Column description. (1) Energy price $p$ in $€ /$ kWh. (2) Revenue (turnover) mean value $\bar{R}$ in $€$, namely, in 000 Euros. (3) Cost mean value $\bar{C}$ in 000 $€$. (4) Cash flow mean value $\bar{F}$ in $000 €$; this is the difference between the two previous columns. (5) $\sigma_{F}=p \sigma_{e}$ in $000 €$. (6) $\theta=(\tilde{F}-\bar{F}) / \sigma_{F}$ where $\bar{F}=0$, namely, zero cash flow standardized under normal distribution. (7) $B(p)=\operatorname{prob}(F \geq 0)$, namely, probability of receiving cash flows greater than (or equal to) zero. (8) $B^{\prime}(p)=\operatorname{prob}(F<0)$, namely, probability of receiving cash flows lower than zero.

This table is used to determine points on the $\mathrm{CP}$ frontier. Each point is computed from the energy price, which appears in column (1). These frontier points range between the $8^{t h}$ and the $13^{\text {th }}$ rows, which are highlighted in bold. These bounds are obtained from the following dialogues.

(i) Simulated dialogue with the government:

-Arbiter/analyst. Which would be the highest energy price acceptable by the government?- 
- G agency. Around 260 euros per kWh -

As this is a simulated dialogue, answer 260 is estimated from observed trends in the guaranteed prices (see subsection 2.2). This answer leads to the $13^{\text {th }}$ row in the table.

(ii) Dialogue (not necessarily simulated) with the sponsor:

- Arbiter/analyst. Consider the probability of receiving positive cash flows. In your opinion, which would be the lowest level acceptable for this probability?-

- Sponsor. Around 0.75.-

This answer leads to the $8^{\text {th }}$ row in the table.

Therefore, the CP frontier points range between the $8^{\text {th }}$ and the $13^{\text {th }}$ rows.

\subsection{Compromise Programming model: Results}

From the theoretical statements in Section 2 and by using the previous numerical information, Table 4 is constructed.

Table 4 Project Ermita: CP solutions (metric 200) from weights $w_{1}=w_{2}=0.5$

\begin{tabular}{ccccc}
\hline$(1)$ & $(2)$ & $(3)$ & $(4)$ & $(5)^{(*)}$ \\
\hline 0.248925 & 0.750000 & 1.000000 & 0.000000 & 0.110519 \\
0.251324 & 0.828510 & 0.783380 & 0.078510 & $\mathbf{0 . 1 0 8 3 1 0}$ \\
0.254056 & 0.895035 & 0.536727 & 0.145035 & 0.231637 \\
0.256787 & 0.939756 & 0.290074 & 0.189756 & 0.354963 \\
0.259519 & 0.967510 & 0.043421 & 0.217510 & 0.478290 \\
0.260000 & 0.971039 & 0.000000 & 0.221039 & 0.500000 \\
\hline
\end{tabular}

Column description. (1) Energy price $p$ in $€ /$ kWh. (2) $B(p)=\operatorname{prob}(F>0)$.

(3) $x_{1}$. (4) $x_{2}$. (5) CP distances from point $\left(x_{1}, x_{2}\right)$ to the ideal point.

$(*)$ Minimum distance is highlighted in bold.

In Table 4, metric 200 is used, as this metric is a proxy for the infinity norm, which is appealing to risk averters. Weights 0.5 are neutral weights, namely, they are not in favor of any of the parties. By using Lingo 11.0 software (an Optimization Modeling Software for Linear, Nonlinear, and Integer Programming, LYNDO Systems), the CP solution is found. In the last column of the table, this solution is highlighted in bold. Thus, the simulated price is $\mathrm{p}=0.251324 € / \mathrm{kWh}$. In year 2010 , when project Ermita is conceived, the guaranteed prices $(€ / \mathrm{kWh})$ set in Spain for photovoltaic energy (type II) were as follows: 0.281045 (first quarter), 0.273178 (second quarter), 0.265509 (third quarter) and 0.258602 (fourth quarter), with an average of 0.269584. From equation (1), the "to invest or not to invest" dilemma is solved by comparing the resulting simulated price to the guaranteed prices just recorded. This 
comparison leads to ratio $\left(p_{0}-p\right) / p=7.27$. Therefore, the CP model advises to move forward with the project.

3.5 Sensitivity analysis

In Table 5, a sensitivity analysis is undertaken for different metrics and weights 0.5 .

Table 5 Project Ermita: Sensitivity analysis $\left(w_{1}=w_{2}=0.5\right)$ for various metrics

\begin{tabular}{cccccccccc}
\hline$p$ & 1 & 2 & 3 & 4 & 5 & 6 & 50 & 100 & 200 \\
\hline 0.248925 & 0.110519 & 0.110519 & 0.110519 & 0.110519 & 0.110519 & 0.110519 & 0.110519 & 0.110519 & 0.110519 \\
0.251324 & 0.179575 & 0.129652 & 0.117748 & 0.113063 & 0.110859 & 0.109728 & 0.108310 & 0.108310 & 0.108310 \\
0.254056 & 0.269639 & 0.234733 & 0.231977 & 0.231679 & 0.231642 & 0.231637 & 0.231637 & 0.231637 & 0.231637 \\
0.256787 & 0.370605 & 0.355308 & 0.354973 & 0.354964 & 0.354963 & 0.354963 & 0.354963 & 0.354963 & 0.354963 \\
0.259519 & 0.480054 & 0.478293 & 0.478290 & 0.478290 & 0.478290 & 0.478290 & 0.478290 & 0.478290 & 0.478290 \\
0.260000 & 0.500000 & 0.500000 & 0.500000 & 0.500000 & 0.500000 & 0.500000 & 0.500000 & 0.500000 & 0.500000 \\
\hline
\end{tabular}

What if the metric changes, other things being equal? Suppose we use metrics from 1 to 5 . Then, we obtain energy price $p=0.248925$. Now, suppose we use metrics from 6 to 200 and higher. Then, the energy price changes to price $p=0.251324$. Therefore, when the choice of metric is limited to high metrics close to the infinity norm, the metric does not influence the results. Thus, the CP model is quite robust.

\section{Concluding remarks}

As a contribution to theory, the method stated in Section 2 can help the decision makers solve the "to invest or not to invest" dilemma by comparing the simulated price to the guaranteed price in investments financed by the government via price-support. It is worth noting that the method can be used not only in the photovoltaic energy field but also for investments in other renewable energy sectors, and even for investments in activities subsidized by the government when the subsidies have an effect equivalent to via pricesupport. Clear examples are farmers' decisions on crops in the framework of guaranteed price-based agricultural policies, which were widely implemented in Europe and other countries during the $20^{\text {th }}$ century. Currently, there are activities in sectors such as education, healthcare, transport, mining and others, which receive government financial support via subsidies that have an effect equivalent to via price-support.

As a contribution to practice, project Ermita is an actual case, which illustrates the method through numerical tables concerning annual energy production, technological coefficients related to this energy and economic variables 
such as stochastic revenues, cash flows and their significant probabilities. This information in detail can help practitioners analyze other photovoltaic power projects and design the CP model to solve the "to invest or not to invest" dilemma.

Further research could be conducted to extend the method to other types of renewable energy. Fuzzy analysis might be used to avoid crisp language in formulating the criteria.

Acknowledgment. We devote this paper to the memory of Professor Enrique Ballestero, who has been a guiding light in our research careers.

\section{Compliance with Ethical Standards}

Conflict of Interest: The authors declare that they have no conflict of interest.

\section{References}

1. Andrews, R.W., Pollard, A., Pearce, J.M.: Improved parametric empirical determination of module short circuit current for modelling and optimization of solar photovoltaic systems. Solar Energy 86(9), 2240-2254 (2012)

2. Anwar, Y., Mulyadi, M.S.: Income tax incentives on renewable energy industry: Case of geothermal industry in USA and Indonesia. African Journal of Business Management $\mathbf{5}(31), 12,264-12,270(2011)$

3. Aouni, B., Kettani, O.: Goal programming model: A glorious history and a promising future. European Journal of Operational Research 133(2), 225-231 (2001)

4. Ballestero, E.: Selecting the CP metric: A risk aversion approach. European Journal of Operational Research 97(3), 593-596 (1997)

5. Ballestero, E.: Project finance: A multicriteria approach to arbitration. Journal of Operational Research Society 51, 183-197 (2000)

6. Ballestero, E.: Compromise programming: A utility-based linear-quadratic composite metric from the trade-off between achievement and balanced (non-corner) solutions. European Journal of Operational Research 182(3), 1369-1382 (2007)

7. Ballestero, E., Pérez-Gladish, B., Arenas-Parra, M., Bilbao-Terol, A.: Selecting portfolios given multiple eurostoxx-based uncertainty scenarios: a stochastic goal programming approach from fuzzy betas. INFOR: Information Systems and Operational Research 47(1), 59-70 (2009)

8. Ballestero, E., Plà-Santamaría, D.: Portfolio selection on the Madrid exchange: A compromise programming model. International Transactions in Operational Research 10(1), 33-51 (2003)

9. Ballestero, E., Pla-Santamaria, D.: Selecting portfolios for mutual funds. Omega 32(5), 385-394 (2004)

10. Ballestero, E., Pla-Santamaria, D.: Grading the performance of market indicators with utility benchmarks selected from Footsie: a 2000 case study. Applied Economics 37(18), 2147-2160 (2005)

11. Ballestero, E., Romero, C.: Portfolio selection: A compromise programming solution. Journal of the Operational Research Society pp. 1377-1386 (1996)

12. Bastian-Pinto, C., Brandão, L., de Lemos Alves, M.: Valuing the switching flexibility of the ethanol-gas flex fuel car. Annals of Operations Research 176(1), 333-348 (2010)

13. Branker, K., Pathak, M., Pearce, J.M.: A review of solar photovoltaic levelized cost of electricity. Renewable and Sustainable Energy Reviews 15(9), 4470-4482 (2011)

14. Casares, F., Lopez-Luque, R., Posadillo, R., Varo-Martinez, M.: Mathematical approach to the characterization of daily energy balance in autonomous photovoltaic solar systems. Energy 72, 393-404 (2014) 
15. Chatterji, A.K., Levine, D.I., Toffel, M.W.: How well do social ratings actually measure corporate social responsibility? Journal of Economics \& Management Strategy 18(1), 125-169 (2009)

16. Copeland, T.E., Weston, J.: Financial theory and corporate policy (1988)

17. Gallagher, K.S.: Why \& how governments support renewable energy. Daedalus 142(1), 59-77 (2013)

18. García-Cascales, M.S., Lamata, M.T., Sánchez-Lozano, J.M.: Evaluation of photovoltaic cells in a multi-criteria decision making process. Annals of Operations Research 199(1), 373-391 (2012)

19. Gupta, S.: Financing renewable energy. In: Energy for Development, pp. 171-186. Springer (2012)

20. van de Kaa, G., Rezaei, J., Kamp, L., de Winter, A.: Photovoltaic technology selection: A fuzzy MCDM approach. Renewable and Sustainable Energy Reviews 32, 662-670 (2014)

21. Karaarslan, A.: Obtaining renewable energy from piezoelectric ceramics using sheppardtaylor converter. International Review of Electrical Engineering 7(2) (2012)

22. Koellner, T., Weber, O., Fenchel, M., Scholz, R.: Principles for sustainability rating of investment funds. Business Strategy and the Environment 14(1), 54-70 (2005)

23. Lorenzo, E., Navarte, L.: On the usefulness of stand-alone pv sizing methods. Progress in Photovoltaics: Research and Applications 8(4), 391-409 (2000)

24. Lüdeke-Freund, F., Loock, M.: Debt for brands: tracking down a bias in financing photovoltaic projects in germany. Journal of Cleaner Production 19(12), 1356-1364 (2011)

25. Mavrotas, G., Diakoulaki, D., Capros, P.: Combined MCDA-IP approach for project selection in the electricity market. Annals of Operations Research 120(1-4), 159-170 (2003)

26. Mendez-Rodriguez, P., Garcia Bernabeu, A., Hilario, A., Perez-Gladish, B.: Some effects on the efficient frontier of the investment strategy: a preliminary approach. Recta 14, 131-144 (2013)

27. Michelson, G., Wailes, N., Van Der Laan, S., Frost, G.: Ethical investment processes and outcomes. Journal of Business Ethics 52(1), 1-10 (2004)

28. Mills, S.J.: Project finance for renewable energy. Renewable energy 5(1-4), 700-708 (1994)

29. ORourke, A.: The message and methods of ethical investment. Journal of Cleaner Production 11(6), 683-693 (2003)

30. Pla-Santamaria, D., Bravo, M.: Portfolio optimization based on downside risk: a meansemivariance efficient frontier from Dow Jones blue chips. Annals of Operations Research 205(1), 189-201 (2013)

31. Richter, N.: Renewable project finance options: Itc, ptc, or cash grant? Power 153(5), 90-92 (2009)

32. Schrader, U.: Ignorant advice-customer advisory service for ethical investment funds. Business Strategy and the Environment 15(3), 200-214 (2006)

33. Sitarz, S.: Compromise programming with tehebycheff norm for discrete stochastic orders. Annals of Operations Research 211(1), 433-446 (2013)

34. Yaqub, M., Shahram Sarkni, P., Mazzuchi, T.: Feasibility analysis of solar photovoltaic commercial power generation in California. Engineering Management Journal 24(4) (2012)

35. Yazdani-Chamzini, A., Fouladgar, M.M., Zavadskas, E.K., Moini, S.H.H.: Selecting the optimal renewable energy using multi criteria decision making. Journal of Business Economics and Management 14(5), 957-978 (2013)

36. Yu, P.: Multiple criteria decision making: Concepts, techniques and extensions (1985)

37. Zeleny, M.: Multiple criteria decision making, vol. 25. McGraw-Hill New York (1982)

38. Zhao, R., Shi, G., Chen, H., Ren, A., Finlow, D.: Present status and prospects of photovoltaic market in China. Energy Policy 39(4), 2204-2207 (2011) 